miRNAs belong to a class of small non-coding RNAs which can modulate gene expression. Disturbances in their expression and function may cause cancer formation, progression and cell response to various types of stress. The let-7 family is one of the most studied groups of miRNAs. The family contains 13 members with similar sequences and a wide spectrum of target genes. In this paper, we mostly focus on one member of the family - let-7d. This miRNA is dysregulated in many types of cancers. It can be over- or down-expressed, and it acts as a tumor suppressor or oncogene. It regulates various genes such as LIN28, C-MYC, K-RAS, HMGA2 and IMP-1. Moreover, let-7d has a significant impact on epithelial-to-mesenchymal transition (EMT) and formation of cancer initiating cells which are resistant to irradiation and chemical exposure and responsible for cancer metastasis. Let-7d can serve as a prognostic and predictive marker for personalization of the treatment. Let-7d is a small RNA with great power, but in different cell genetic backgrounds it acts in different ways, which makes this molecule still mysterious.

Key words: let-7d, let-7 family, miRNA, gene regulation, cancer, radiotherapy, chemotherapy.

Contemp Oncol (Pozn) 2014; 18 (5): 293-301 DOI: $10.5114 /$ wo.2014.44467

\section{The mystery of let-7d - a small RNA with great power}

\author{
Tomasz Kolenda ${ }^{1,2}$, Weronika Przybyła ${ }^{1}$, Anna Teresiak ${ }^{1}$, \\ Andrzej Mackiewicz ${ }^{3,4}$, Katarzyna M. Lamperska ${ }^{1}$
}

${ }^{1}$ Laboratory of Cancer Genetics, Greater Poland Cancer Centre, Poznan, Poland ${ }^{2}$ Postgraduate School of Molecular Medicine, Medical University of Warsaw, Poland ${ }^{3}$ Department of Cancer Immunology, Chair of Medical Biotechnology, Poznan University of Medical Sciences, Poznan, Poland

${ }^{4}$ Department of Diagnostics and Cancer Immunology, Greater Poland Cancer Centre, Poznan, Poland

\section{MicroRNAs}

miRNAs are a group of short, about 22 nucleotides long, non-coding RNAs. miRNA genes are situated within the introns or exons of coding genes or in intergenic regions [1]. They may possess their own promoters or share them with mRNA translation promoters. Some miRNAs are encoded as a single miRNA, others as multiple miRNAs creating clusters [2]. miRNA genes are transcribed from the genome by RNA polymerase II or III. The biogenesis of miRNAs is still not clear, but generally two different pathways of miRNA biogenesis are distinguished: "canonical" and "non-canonical". The canonical one is a two-stage process occurring in the nucleus and cytoplasm, where immature forms of miRNA hairpins are transformed to about 22 nt duplexes by Drosha and Dicer enzymes. One of the duplex strands, called the guide strand, is incorporated into the RISC complex, and miRNA in this complex can bind with the 3'UTR region of target mRNA [3-9]. Some data suggest that the second strand, miRNA*, can also take part in the regulation of gene expression [10, 11].

Regulation of gene expression is the function of miRNAs and is connected with two mechanisms of blocking protein translation: i) repression of mRNA translation or ii) cleavage of mRNA. miRNAs can regulate from $30 \%$ to $60 \%$ of human genes [12]. These small RNAs are associated with the cell cycle, apoptosis, proliferation, differentiation, metabolic pathways and cell response to various types of stress [13-18]. The relationship of miRNAs between important cellular processes and disturbance of miRNA expression, biogenesis, and function in cancer makes these small molecules one of the most studied nowadays.

\section{Let-7d}

The human lethal-7 (let-7) family plays a critical role in regulation of development and carcinogenesis. The family contains 13 members located in 9 different loci on chromosomes 3, 9-12, 19, 21, 22 and X (Fig. 1A) [19]. Let-7 miRNAs are the most abundant among all miRNAs [19]. They are conserved across species and are considered as an ancient miRNA [120]. They are located individually or as clusters, which can contain only let-7 members or also other miRNAs. Clusters are the result of vertebrate-specific genome duplications [20], which enable correct biogenesis of miRNAs and also precise regulation of them [2]. All members of the family are highly sequence-similar and share a common nucleotide motif named the "seed region", which is a crucial component for target recognition by RISC [4-6].

Let-7d is one of the members of this family. It is situated within the let$7 \mathrm{a}-1 /$ let-7f-1/let-7d cluster, which is located in the human genome in region 
B on chromosome 9q22.3. The cluster with a $10 \mathrm{~kb}$ upstream promoter encodes a single polycistronic transcript with 3 members, which constitute about $24 \%$ of all let- 7 precursors [19]. The transcriptional activity of the promoter is nearly as strong as SV40. The cluster contains two MYC-binding sites. Binding of MYC protein to non-canonical E-box 3 causes inhibition of transcription, whereas binding to canonical E-box 2 enhances this process (Fig. 1C). Binding to E-boxes depends on the cancerous or non-cancerous cell character and ratio of MYC and MAX in the nucleus [19].

The post-transcriptional regulation of let-7 miRNAs is carried out on LIN28 and LIN28B. LIN28 binds to preE elements of the miRNA transcript and blocks pri-let-7 processing by Drosha and pre-let-7 by Dicer. Furthermore, LIN28 can recruit a terminal uridylyl transferase which adds uridine to pre-miRNA and causes its decay. LIN28 is associated with aggressive forms of cancer and causes down-regulation of let-7 miRNAs, especially the let-7f precursor [19, 21, 22]. Let-7d may be similarly regulated by an androgen effect in prostate cancer [23] and by PDGF in glioblastoma and ovarian cancer [24]. It is possible that, like in nematode worms, regulation of let-7 is controlled by let- 7 itself. Mature let- 7 with its effector protein, Argonaute, as miRISC can bind to pri-let-7 [25, 26].

\section{Let-7d targets}

The mature let-7 family members are the most abundant among all miRNAs in the cell and they are regulated by different transcriptional and post-transcriptional mechanisms. The characteristic feature of miRNAs from one family is sharing an identical seed sequence (Fig. 1B), so different members of the let-7 family could possess overlapping targets. Moreover, nucleotide changes in the pre-let-7 precursor make its stem fully complementary, whereby it functions as SiRNA $[27,28]$. There is a lack of comprehensive studies describing targets for all let- 7 members and explaining whether all members regulate the same genes. Here, we focus on let-7d, which has only a few experimentally proven targets.

Let-7 family members are direct and strong regulator of the RAS family. K-RAS, N-RAS and H-RAS mRNAs contain let-7 binding sites in 3'UTR sequences [29, 30]. Inhibition of K-RAS mRNA by let-7d causes greater accumulation of cells in G1 than in G2/M phase of the cell cycle whereby cell proliferation is reduced [30].

The second known target is MYC [29]. There is a double-negative feedback loop between MYC and let-7 miRNAs. MYC expression is inhibited by let-7d, whereas MYC inhibits some members of the let-7 family. Moreover, the inhibitory function of MYC is shared with LIN28, which is involved in induced pluripotent stem cell (iPS) and tumor initiating cell (TIC) formation [19, 21, 29].

IMP-1 is also a target of the let-7 family. There is a connection among let-7, IMP-1 and MYC. Let-7 can reduce MYC protein expression directly by binding to its 3'UTR or indirect by depletion of IMP-1, which in turn destabilizes MYC mRNA. IMP-1 also regulates cell-cycle CDC25A and CDK6 $[29,31]$.
The next target of let-7 is HMGA2. This oncogene can skip let-7 regulation by loss of its let-7 binding sites, causing over-expression of this protein and leading to tumor formation [29]. Moreover, HMGA2 mRNA in some cases is a more sensitive target of let-7 than RAS [32].

The group of genes regulated by let-7d also includes cell-cycle genes such as CDC25A, CDK6 and cyclin D1 [29]. The microarray analysis of gene expression in cells with let-7b over-expression indicates down-regulation of genes associated with cell cycle and division (cyclins, cell division cycle proteins, kinase-associated proteins) as well as genes coding for DNA synthesis and DNA replication. Surprisingly, let-7b causes inhibition of expression of both proven and putative tumor suppressor genes and the cell cycle checkpoint genes. On the other hand, let-7b up-regulates some genes such as the CDK inhibitor B2, MAX and cyclin G2, so it can act as a tumor suppressor [33]. Let-7c and let-7g regulate $\mathrm{BCl}_{-\mathrm{xL}}$ - an anti-apoptotic member of the $\mathrm{Bcl}$ family [34]. Let-7d is presumable engaged in Dicer protein regulation and lack of it causes over-expression of this enzyme and proliferation of cancer cells in the oral cavity [35]. PBX3 [23], DMT1 [36] and caspase-3 [37, 38] are also indicated as let-7d targets. The long list of let-7 family targets, their functions and relation with cancer have been reviewed by Barh [39].

Taking into consideration only the seed region, let-7d should regulate the same targets as other family members. However, emerging data suggest that the let-7 family contains miRNAs with different activities [28]. Some evidence suggests that miRNAs from the same precursor target different genes, which are involved in different cellular processes [2]. The gene targeting is made more complicated by the existence of 3' and 5' variants of one miRNA (isomiRs) created by Drosha and/or Dicer enzymes. The 3' end of miRNAs can be modified by exoribonucleases as well as nucleotidyltransferases, and RNA editing can cause modification of the "seed region". All of these events produce different variants of one mature miRNA, which could have different targeting properties [2, 40]. The inhibition of proteins depends largely on the cell genetic background, and let-7 members might cause different degrees of translation inhibition and mRNA instability depending on target genes [32, 33]. Moreover, some miRNAs probably can not only inhibit but also up-regulate protein levels. Let-7 belongs to the group of these miRNAs [41]. There is still a lack of precise knowledge about let-7 targets as well as full understanding of let-7 family members function. Some of the targets of let-7d predicted by TarBase (DIANA Tools) and miRDB have been shown in Table $1 A$ and for let-7d* in Table 1B. The analysis reveals over 300 target genes for let-7d-5p and 40 for let-7d-3p.

\section{Let-7d and cancer}

Half of the known miRNA genes are located close to or inside chromosomes regions, which are usually mutated in cancer, known as fragile sites and cancer-associated genome regions $[42,43]$. Single miRNA can function in cancer as a tumor suppressor or oncogene (oncomiR), or have dual function. Down-regulation of suppressor miRNAs and 
A
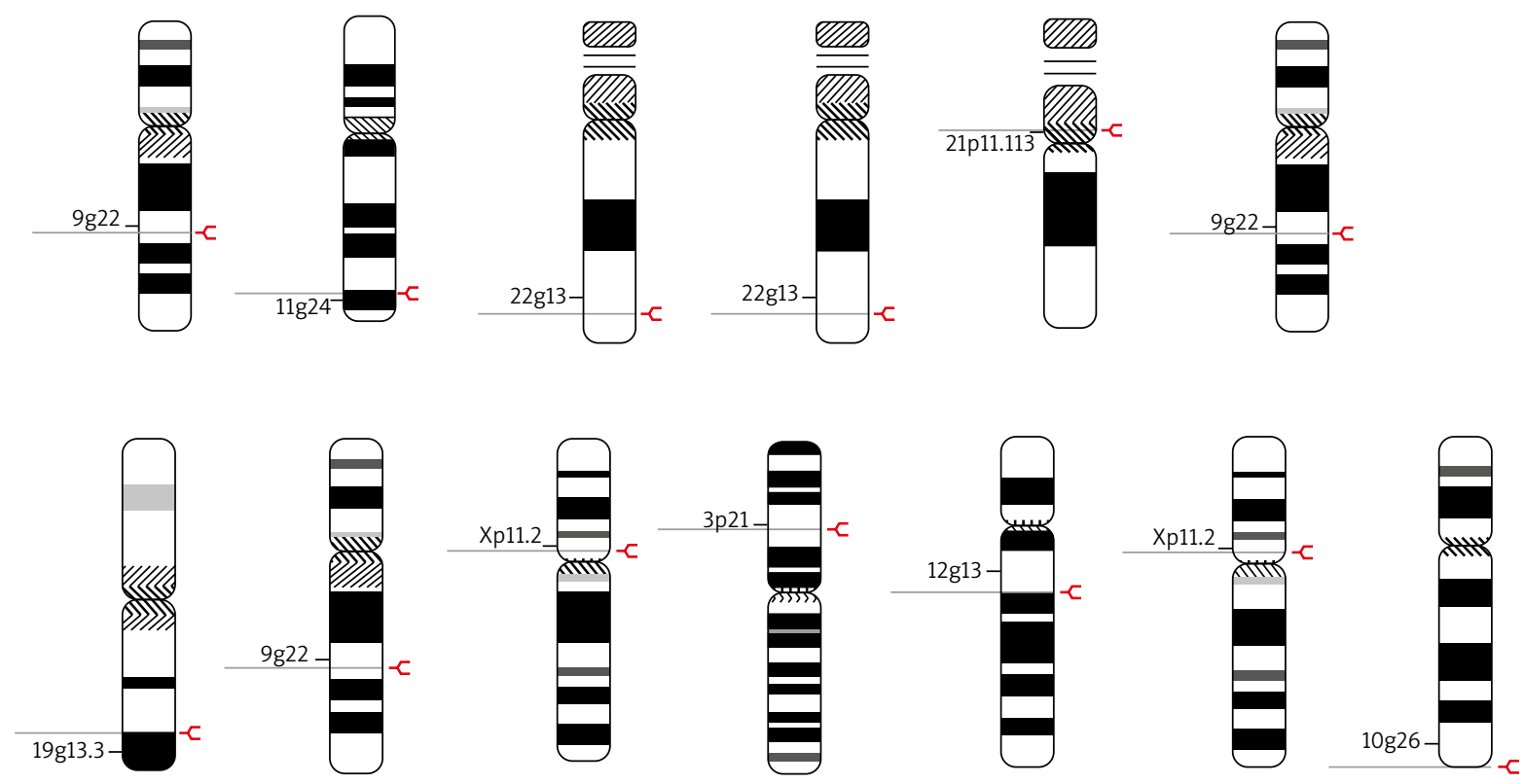

B

$\begin{array}{lll}\text { miRNA } & \text { miRBase number } & \text { Sequence } \\ \text { hsa-let-7a-1 } & \text { M10000060 } & \text { GGGAUGAGGUAGUAGGUUGUAUAGUU } \\ \text { hsa-let-7a-2 } & \text { M10000061 } & \text { AGGUUGAGGUAGUAGGUUGUAUAGUU } \\ \text { hsa-let-7a-3 } & \text { M10000062 } & \text { UGAGGUAGUAGGUUGUAUAGUU } \\ \text { hsa-let-7b } & \text { M10000063 } & \text { UGAGGUAGUAGGUUGUGUGGU } \\ \text { hsa-let-7c } & \text { M10000064 } & \text { UGAGGUAGUAGGUUGUAUGGUU } \\ \text { hsa-let-7d } & \text { M10000065 } & \text { AGAGGUAGUAGGUUGCAUAGUU } \\ \text { hsa-let-7e } & \text { M10000066 } & \text { UGAGGUAGGAGGUUGUAUAGUU } \\ \text { hsa-let-7f-1 } & \text { M10000067 } & \text { UCAGAGUGAGGUAGUAGAUUGUAUAGUU } \\ \text { hsa-let-7f-2 } & \text { M10000068 } & \text { GUCGGAUGAGGUAGUAGAUUGUAUAGUU } \\ \text { hsa-let-7g } & \text { M10000433 } & \text { UGAGGUAGUAGUUUGUACAGUU } \\ \text { hsa-let-7i } & \text { M10000434 } & \text { UGAGGUAGUAGUUUGUGCUGUU } \\ \text { hsa-mir-98 } & \text { M10000100 } & \text { UGAGGUAGUAAGUUGUAUUGUU } \\ \text { hsa-mir-202 } & \text { M10000130 } & \text { UUCCUAUGCAUAUACUUCUUUG }\end{array}$

C

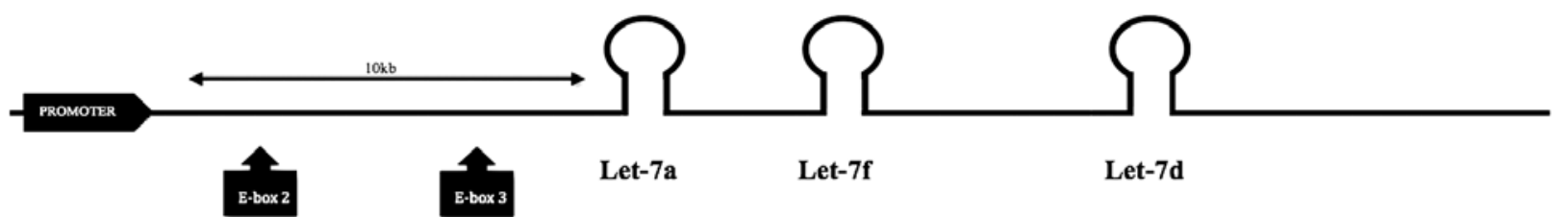

Fig. 1. Characterization of let-7 family: A) genomic localization of its members; arrows show exact localization of miRNA within chromosome; B) sequence similarity and C) structure of let-7a-1/let-7f-1/let-7d cluster. Data obtained from GenBank (NCBI) and miRBase databases 
up-regulation of oncomiRs is linked to initiation of proliferation, invasion, angiogenesis and metastasis of tumor [44-49].

Let-7d is involved in regulation of many important genes, as described in the previous section, so it is not surprising that it has a significant role in cancer. It is believed that members of the let-7 family act as tumor suppressor miRNAs and regulate expression of many oncogenes by both direct and indirect pathways [28]. Expression levels of let-7 family members are significantly low in human cancers, but in some cases high expression levels are indicated [39]. The mechanism of this phenomenon is still not clear, but it is probably connected with complex let-7 family transcription and post-transcription regulations, genes' copy number of let-7 members and epigenetic modulations [50,51]. It has been proven that deletion of some let7 miRNAs or let-7 clusters is cancer-type dependent [50].

The expression of let-7d is deregulated in cancers such as pancreatic, prostate, primary pigmented nodular adrenal dysplasia, head and neck, ovarian, breast, bladder, kidney and retinoblastoma [28, 39, 52-54].

The implications of the let-7 family in cancer are multifaceted due to regulation of the cell cycle, proliferation, and apoptosis pathways, as described above. Moreover, the let-7 family has an influence on differentiation, epithelial-to-mesenchymal transition (EMT) and TIC formation [55-57].

Over-expression of let-7d causes cell differentiation and changes in cell phenotype in vitro. For example, neural stem cells transfected by let-7d differentiated into astroglial cells. The proliferation of neural stem cells has been suppressed and cell migration in mouse brain has been observed. Let$7 d$ regulates these effects on neurogenesis by modulating miR-9 and TLX [58]. The other studies showed, that fibroblasts are less mesenchymal-like and more similar to epithelial cells. In this case let-7d partly changed cell phenotype, probably by affecting HMGA2, SLUG, ID1 and ID2, but did not influence TWIST and SNAIL $[59,60]$. On the other hand, inhibition of let-7d upregulates HMGA2 and some markers characteristic for mesenchymal cells. Moreover, let-7d seems to be under direct transcriptional regulation of transforming growth factor $\beta$ (TGF- $\beta$ ) [61]. Let-7d functions as a switch between EMT and MET (mesenchymal-epithelial transition) processes and regulates the TIC cell population.

The TICS are a small fraction of tumor cells displaying the capacity for self-renewal and differentiation into new cancer cells. Highly tumorigenic behavior and radio- and chemoresistance are their features. The let-7 family is down-regulated by post-transcriptional mechanisms in TICS and up-regulated during the differentiation process. In the group of let-7 oncofetal genes suppressed in most adult tissues but activated in various forms of cancer are HMGA2 (promotes self-renewal of stem cells), IMP-1 (stabilizes some RNAs such as C-MYC and protects them from degradation), LIN28/LIN28B (responsible for pluripotency), RAS and MYC [56]. Down-regulation of let-7d in head and neck squamous cell carcinoma lines activated TWIST and SNAIL expression, whereas up-regulation of let-7d reversed the phenotype. Modulation of let-7d changed the cell nature and controlled ALDH+/-cell populations, where $\mathrm{ALDH}+$ cells are described as TICs [55].
It is proven that the let-7 family has a significant role in cancer biology, but it is not explained whether disturbance of let-7 miRNA expression causes cancer transformation or these disturbances are caused by cancerous changes in the cell. It is also not clear why, in some cancer, expression of let-7 members is down- or up-regulated. Some independent studies regarding the same cancer type indicated both possibilities: for example, let-7d is indicated as up- as well as down-regulated in prostate cancer [62]. Sometimes let-7 profiling is much more complicated, because in the same cancer patient group, cases with low, unchanged and high let-7 expression can be found [62]. It is accepted that let-7 miRNAs are suppressors, and this statement is supported by many observations and experimental studies. However, we can also find evidence for the oncogenic role of some let-7s as a result of targeting caspase-3 $[37,38]$ and BAX mRNAs $[63,64]$. Is it possible to definitely say what is the exact role of let-7 family members in cancer: suppressor or oncogene or maybe both of them? What affects the role of let-7 miRNAs in cancer cells? These questions are still open.

\section{Let-7d and response to irradiation and chemical exposure}

Studies have shown dual behavior of the let-7 family after irradiation - miRNAs of this family can be up- or down-regulated $[65,66]$. The behavior of let-7 members (like other miRNAs) depends on dose, time after irradiation, source of oxidative stress and genetic background of the cell [67-69]. For example, in two glioblastoma cell lines, with different DNA-PK activity, that let-7 members (including let-7d) are mostly up-regulated in that cell line which is more radioresistant [67]. In contrast, in lung cancer cell lines let-7 members (including let-7d) are mostly down-regulated [54].

The let-7 members regulate C-MYC and RAS expression. It has been shown that C-MYC or N-RAS alone increases radiation sensitivity, whereas together they increase radioresistance [70]. Down-regulation of let-7 family members depends on the dose and may be regulated directly by 553 as well as indirectly by ATM protein. The let-7 family seems to be a critical factor for the cellular response to oxidative stress and is potentially involved in protection against radiation cytotoxicity. In contrast, over-expression of let-7a causes decreased K-RAS expression and radiosensitization of cells. The RAS protein is regulated through the Lin28-let-7 network [71]. The let-7 family's impact on radiosensitivity has been confirmed in vitro [72]. Over-expression of let-7 affects the RAS oncogene and genes associated with DNA damage repair: RAD51, RAD21, FANCD2 and CDC25 [72]. Different patterns of miRNA expression have been shown in irradiated and bystander cells. The let-7 family is up-regulated in irradiated cells as opposed to bystander cells, in which most of these miRNAs are repressed [73]. The changes in miRNA expression can be observed just a few minutes after irradiation. Some authors report that peaks of up- or down-regulation are found at 4 hours after irradiation, at the time of the most active DNA repair processes. Most of the miRNAs return to their baseline levels after 24 hours $[68,69,74]$. Changes of miRNAs 
Table 1. Predicted target genes for: A) let-7d-5p and B) for let-7d-3p (let-7 $\left.d^{\star}\right)$. Let-7d-5p has over 300 and let-7d-3p has 40 predicted target genes. Some of them have been experimentally validated. Data obtained from miRDB and TarBase databases. Target scores equal to and over 0.8 (for A) and 0.7 (for B) have been choosen as criteria for let-7d targets; *target score taken from TarBase

A

\begin{tabular}{|c|c|c|c|}
\hline Target score & Validated by & Gene symbol & Gene description \\
\hline $0.96 / 0.99^{*}$ & sequencing & LIN28B & lin-28 homolog B (C. elegans) \\
\hline $0.971^{*}$ & sequencing & ZNF280B & zinc finger protein $280 \mathrm{~B}$ \\
\hline $0.969^{*}$ & sequencing & SLC20A1 & solute carrier family 20 (phosphate transporter), member 1 \\
\hline $0.965^{\star}$ & sequencing & TMEM135 & transmembrane protein 135 \\
\hline $0.955^{\star}$ & sequencing & IGF1R & insulin-like growth factor 1 receptor \\
\hline $0.951^{*}$ & sequencing & KPNA5 & karyopherin alpha 5 (importin alpha 6) \\
\hline $0.939^{\star}$ & sequencing & HAND1 & heart and neural crest derivates expressed 1 \\
\hline $0.939^{*}$ & sequencing & TGFBR1 & transforming growth factor, beta receptor 1 \\
\hline $0.931^{*}$ & sequencing & SMARCAD1 & $\begin{array}{l}\text { SWI/SNF-related, matrix-associated actin-dependent regulator of chromatin, } \\
\text { subfamily a, containing DEAD/H box } 1\end{array}$ \\
\hline $0.922^{*}$ & sequencing & USP24 & ubiquitin specific peptidase 24 \\
\hline 0.920 & & LRIG3 & leucine-rich repeats and immunoglobulin-like domains 3 \\
\hline 0.920 & & DDI2 & DNA-damage inducible 1 homolog 2 (S. cerevisiae) \\
\hline $0.911^{*}$ & sequencing & ONECUT2 & one cut homebox 2 \\
\hline $0.896^{\star}$ & sequencing & SLC10A7 & solute carrier family 10 , member 7 \\
\hline $0.89 / 1.00^{*}$ & sequencing & IGF2BP1 & insulin-like growth factor 2 mRNA binding protein 1 \\
\hline $0.880^{*}$ & sequencing & ARID3A & AT rich interactive domain $3 \mathrm{~A}$ \\
\hline 0.880 & & PRTG & protogenin \\
\hline $0.872^{*}$ & sequencing & SPRYD4 & SPRY domain containing 4 \\
\hline 0.870 & $\begin{array}{l}\text { expression } \\
\text { observation }\end{array}$ & HMGA2 & high mobility group AT-book 2 \\
\hline $0.869^{*}$ & sequencing & FAM104A & family with sequence similiarity 104 , member $\mathrm{A}$ \\
\hline 0.850 & & NAP1L1 & nucleosome assembly protein 1 -like 1 \\
\hline 0.850 & & USP38 & ubiquitin specific peptidase 38 \\
\hline 0.850 & & COIL & coilin \\
\hline $0.847^{*}$ & sequencing & C11orf57 & chromosome 11 open reading frame 57 \\
\hline $0.842^{*}$ & sequencing & ZNF644 & zinc finger protein 644 \\
\hline 0.840 & & LIMD2 & LIM domain containing 2 \\
\hline 0.840 & & ADRB2 & adrenergic, beta-2 receptor, surface \\
\hline 0.830 & & DCLRE1B & DNA cross-link repair 1B \\
\hline 0.830 & & GATM & glycine amidinotransferase (L-arginine: glycine amidinotranserase) \\
\hline 0.830 & & FIGNL2 & fidgetin-like 2 \\
\hline $0.830^{*}$ & & IGDCC4 & immunoglobulin superfamily, DCC subclass, member 4 \\
\hline $0.822^{*}$ & & GLMN & glomulin, FKBP associated protein \\
\hline 0.820 & & COL14A1 & collagen, type XIV, alpha 1 \\
\hline 0.820 & & $\mathrm{DMD}$ & dystrophin \\
\hline $0.815^{*}$ & sequencing & NHLRC3 & $\mathrm{NHL}$ repeat containing 3 \\
\hline 0.810 & & SLC5A9 & solute carrier family 5 (sodium/glucose cotransporter), member 9 \\
\hline 0.800 & & GDF6 & growth differentiation factor 6 \\
\hline 0.800 & & MAP4K3 & mitogen-activated protein kinase 3 \\
\hline
\end{tabular}

\section{B}

\begin{tabular}{|c|c|c|c|}
\hline Target score & Validated by & Gene symbol & Gene description \\
\hline 0.840 & & MEX3C & mex-3 homolog C (C. elegans) \\
\hline 0.810 & & NOM1 & nucleolar protein with MIF4G domain 1 \\
\hline 0.760 & & SH3RF1 & SH3 domain containing ring finger 1 \\
\hline 0.730 & & PTAR1 & protein prenyltransferase alpha subunit repeat containing 1 \\
\hline 0.730 & & KIAA1267 & KIAA1267 \\
\hline 0.710 & & PARP11 & poly (ADP-ribose) polymerase family, member 11 \\
\hline
\end{tabular}


after irradiation can be a result of cell protection causing increased expression of genes responsible for DNA repair and decreased levels of pro-apoptotic genes. However, it is possible that miRNAs in irradiated cells tend to return to levels of genes changed after stress. Nonetheless, the exact regulatory mechanisms and role of miRNAs in response to irradiation still remain unclear.

Loss of let-7 family function is associated with drug resistance in various cancers. The known mechanisms are both direct and indirect. The direct influence of let-7c and let-7g is based on targeting 3'UTR of Bcl- ${ }_{x L}$, which leads to its decrease in human hepatocellular carcinoma. Up-regulation of let- 7 sensitizes cells to sorafenib by targeting $\mathrm{MCl}-1$, a member of the $\mathrm{BCl}-2$ anti-apoptotic family [34]. Another direct effect of let-7 (let-7a and let-7d) is connected with inhibition of caspase-3. Two independent studies reported that let-7 has a complementary seed sequence to 3'UTR of caspase-3 mRNA [37, 38]. The regulation by let-7 refers to the caspase- 3 only but not to caspase- 8 or -9 . In this case, over-expression of let-7a reduces sensitivity of cells to agents such as doxorubicin, paclitaxel or interferon $\gamma$. In this context, let- 7 acts as an oncomiR instead of a suppressor miRNA [38]. The high let-7a expression and paclitaxel treatment may together stimulate expression of IGF-II. High expression of IGF-II causes progression of ovarian cancer. However, let-7a may synergistically interact with platinum drugs by inhibition of DNA repair systems such as BRCA1. In this context, high expression of let-7a supports the platinum effect [75].

The indirect influence of let-7g via IMP1 stabilizes mRNA of MDR-1. The MDR-1 (ABCB1) gene, a member of ATP binding cassette transporters ( $A B C$ transporter family), encodes the membrane transporter P-glycoprotein responsible for multidrug resistance [76]. The regulator of miRNA biogenesis LIN28 is up-regulated in breast cancer cells which are resistant to paclitaxel. As mentioned above, LIN28 causes down-regulation of let-7a and let-7b and induces expression of p21 and RB. There is a feedback loop between let-7 and LIN28 regulating cell phenotype. Over-expression of LIN28 is characteristic for TICS, local relapse and metastasis of cancer. Moreover, the expression of LIN28 dramatically increases in cancer tissue after neoadjuvant chemotherapy. Restoring let-7 expression increases sensitivity to paclitaxel [77]. In head and neck cancers, over-expression of let-7d and let-7a reduces chemoresistance by depletion of TICS with ALDH+ phenotype and sensitizes to cisplatin and 5-FU $[55,78]$.

In sum, there is limited knowledge about the role of let-7d in the cell response to radiation and chemotherapeutic drugs. The exact function is not determined, and potentially let-7d may function like other members of the let-7 family by targeting the same pathways. Experimental studies should dispel doubts about this phenomenon.

\section{Let-7d in diagnostics and treatment}

The members of the let-7 family are connected with many features of cancer and could be applied as diagnostic, predictive and prognostic biomarkers.

Let-7d alone or together with other genes may be used for cancer profiling and serve as a diagnostic marker.
The cancers can be divided into two groups: let- $7^{\text {high }}$ - and let- $7^{\text {low-expressing. The let-7 }}{ }^{\text {high }}$ cancers are more differentiated and display an epithelial phenotype [79]. But in contrast, let-7d is up-regulated in invasive ductal carcinoma [80]. These data suggest that the level of let-7 expression is not a universal marker of tumor aggressiveness. Even so, changes in let-7 still seem to be a marker of cancer transformation and progression [81] and enable cancer to be distinguished from normal tissue and different pathological types of tumor [82]. The use of miRNA seems to be a more sensitive tool than the currently used histopathological methods.

It has been shown that modification of let-7d level caused changes in cell line resistance to cisplatin and 5-FU [55]. There is no clinical study about let-7d's influence on chemotherapy. However, analysis of let-7a levels in ovarian cancer patients can be used as a predictive marker. The patients with high expression of let-7a respond better to platinum treatment. Combined treatment, platinum with paclitaxel, is more beneficial for patients with low let-7a expression [75].

A combined low level of let-7d and miR-205 is a poor prognostic marker in head and neck cancer patients, and it seems to be independent of anatomical site, tumor size, treatment and HPV status [83]. Similarly, ovarian cancer patients with a low combined score of HMGA2 and let-7d have better prognosis than the group with a high HMGA2/ let-7d ratio [79]. Likewise, assessment of let-7 $d^{*}$ expression can be used as a predictor of recurrence risk for hepatocellular carcinoma [84]. In contrast to this, pancreatic cancer patients with a high level of let-7d in plasma have the worst prognosis, but the authors of the study normalized the results to miR-16 [85], which is a poor normalizing factor [88].

The diagnostics tends to use biomarkers which can be simply achieved from the patients at any time during treatment. Circulating miRNAs from whole blood or serum can be used as non-invasive biomarkers for hematological malignancies and solid tumor detection [86, 87]. However, one of the emerging problems of circulating miRNAs is their normalization. The use of a combination of let-7d/ let-7g/let-7i as normalization control for circulating miRNAs is supposed to be a more reliable solution than commonly used reference genes [88].

Restoration of a member or members of the let-7 family in cancer cells is a new promising gene therapy. Restoration of let-7d should inhibit cancer proliferation and metastasis, deplete TICs and sensitize to chemo- and radiotherapy. The delivery of anti- or miRNAs is based on viral and non-viral vehicles [89-93]. Some preclinical and clinical studies with let-7 members are currently in progress [94-96]. The application of miRNAs in cancer therapy may prove to be superior to siRNAs or shRNAs because interfering miRNA (miRNAi) modifies overlapping targets containing complementary regions to the seed sequence of miRNA in a natural way [97]. The effect is mild and simultaneous on a number of oncogenes and pathways [50]. The introduction of artificial miRNAs may be less toxic than traditional chemotherapy. The eventual off-target effect and toxicity caused by miRNA are mild or negligible $[98,99]$. 


\section{Summary}

Even though miRNAs are among the most analyzed molecules nowadays, the let-7 family still seems to be mysterious. The family contains 13 members with almost identical sequences and ability to regulate different targets. Moreover, one let-7 member regulates various genes. The behavior of let- 7 members can depend on their activity, genetic cell context or tumor microenvironment. They are deregulated in various cancers by different mechanisms, and their function is not fully defined. The members may display different functions in the same cell and sometimes can behave as a suppressor or an oncogene. Many studies have shown that the let-7 family is implicated in proliferation, invasion, angiogenesis and tumor metastasis, can change cell phenotype through the EMT process, and regulates TIC populations. Multifaceted let-7 modulates cancer response to radio- and chemotherapy. However, there is a lack of comprehensive studies about all members. Knowledge about the role of individual members, such as let-7d, is based on assumptions and comparisons to other members of the family.

The potential of the family probably can be used for early cancer diagnostics, prediction, treatment personalization and new therapeutic miRNA technology in the future, but firstly, we should reveal the secrets about all members of the let-7 family.

This work was supported by the Greater Poland Cancer Center-grant No. 9/2012 (51).

The authors declare no conflict of interest.

\section{References}

1. Bartel DP. MicroRNAs: genomics, biogenesis, mechanism, and function. Cell 2004; 116: 281-97.

2. Marco A, Ninova M, Griffiths-Jones S. Multiple products from microRNA transcripts. Biochem Soc Trans 2013; 41: 850-4.

3. Yang JS, Lai EC. Alternative miRNA biogenesis pathways and the interpretation of core miRNA pathway mutants. Mol Cell 2011; 43: 892-903.

4. Hibio N, Hino K, Shimizu E, Nagata Y, Ui-Tei K. Stability of miRNA 5 'terminal and seed regions is correlated with experimentally observed miRNA-mediated silencing efficacy. Sci Rep 2012; 2: 996.

5. Brennecke J, Stark A, Russell RB, Cohen SM. Principles of microRNA-target recognition. PLoS Biol 2005; 3: e85.

6. Grimson A, Farh KK, Johnston WK, Garrett-Engele P, Lim LP, Bartel DP. MicroRNA targeting specificity in mammals: determinants beyond seed pairing. Mol Cell 2007; 27: 91-105.

7. Havens MA, Reich AA, Duelli DM, Hastings ML. Biogenesis of mammalian microRNAs by a non-canonical processing pathway. Nucleic Acids Res 2012; 40: 4626-4640.

8. Finnegan EF, Pasquinelli AE. MicroRNA biogenesis: regulating the regulators. Crit Rev Biochem Mol Biol 2013; 48: 51-68.

9. Starega-Roslan J, Koscianska E, Kozlowski P, Krzyzosiak WJ. The role of the precursor structure in the biogenesis of microRNA. Cell Mol Life Sci 2011; 68: 2859-2871.

10. Guo L, Lu Z. The fate of miRNA* strand through evolutionary analysis: implication for degradation as merely carrier strand or potential regulatory molecule? PLoS One 2010; 5: e11387.

11. Yang JS, Phillips MD, Betel D, Mu P, Ventura A, Siepel AC, Chen KC, Lai EC. Widespread regulatory activity of vertebrate microRNA* species. RNA 2011; 17: 312-26.
12. He L, Hannon GJ. MicroRNAs: small RNAs with a big role in gene regulation. Nat Rev Genet 2004; 5: 522-31.

13. Bueno MJ, Malumbres M. MicroRNAs and the cell cycle. Biochim Biophys Acta 2011; 1812: 592-601.

14. Bueno MJ, Pérez de Castro I, Malumbres M. Control of cell proliferation pathways by microRNAs. Cell Cycle 2008; 7: 3143-8.

15. Chen D, Farwell MA, Zhang B. MicroRNA as a new player in the cell cycle. J Cell Physiol 2010; 225: 296-301.

16. Kloosterman WP, Plasterk RH. The diverse functions of microRNAs in animal development and disease. Dev Cell 2006; 11: 441-50.

17. Miska EA. How microRNAs control cell division, differentiation and death. Curr Opin Genet Dev 2005; 15: 563-8.

18. Wienholds E, Plasterk RH. MicroRNA function in animal development. FEBS Lett 2005; 579: 5911-22.

19. Wang Z, Lin S, Li JJ, et al. MYC protein inhibits transcription of the microRNA cluster MC-let-7a-1 let-7d via noncanonical E-box. J Biol Chem 2011; 286: 39703-14.

20. Hertel J, Bartschat S, Wintsche A, Otto C; Students of the Bioinformatics Computer Lab, Stadler PF. Evolution of the let-7 microRNA family. RNA Biol 2012; 9: 231-41.

21. Sakurai M, Miki Y, Masuda M, Hata S, Shibahara Y, Hirakawa H, Suzuki T, Sasano H. LIN28: a regulator of tumor-suppressing activity of let-7 microRNA in human breast cancer. J Steroid Biochem Mol Biol 2012; 131: 101-6.

22. Nam Y, Chen C, Gregory RI, Chou JJ, Sliz P. Molecular basis for interaction of let-7 microRNAs with Lin28. Cell 2011; 147: 1080-91.

23. Ramberg H, Alshbib A, Berge V, Svindland A, Taskén KA. Regulation of PBX3 expression by androgen and Let-7d in prostate cancer. Mol Cancer 2011; 10: 50.

24. Shao M, Rossi S, Chelladurai B, Shimizu M, Ntukogu O, Ivan M, Calin GA, Matei D. PDGF induced microRNA alternations in cancer cells. Nucleic Acids Res 2011; 39: 4035-47.

25. Pasquinelli AE. The primary target of let-7 microRNA. Biochem Soc Trans 2013; 41: 821-4.

26. Zisoulis DG, Kai ZS, Chang RK, Pasquinelli AE. Auto-regulation of miRNA biogenesis by let-7 and Agronaute. Nature 2012; 486: 541-4.

27. Steiner FA, Hoogstrate SW, Okihara KL, Thijssen KL, Ketting RF, Plasterk RH, Sijen T. Structural features of small RNA precursors determine Argonaute loading in Caenorhabditis elegans. Nat Struct Mol Biol 2007; 14: 927-33.

28. Boyerinas B, Park SM, Hau A, Murmann AE, Peter ME. The role of let-7 in cell differentiation and cancer. Endocr Relat Cancer 2010; 17: F19-36.

29. Büssing I, Slack FJ, Grosshans H. Let-7 microRNAs in development stem cells and cancer. Trends Mol Med 2008; 14: 400-9.

30. Yu ML, Wang JF, Wang GK, You XH, Zhao XX, Jing Q, Qin YW. Vascular smooth muscel cell proliferation is influenced by let-7d microRNA and its interaction with KRAS. Circ J 2011; 75: 703-9.

31. Boyerinas B, Park SM, Murmann AE, et al. Let-7 modulates acquired resistant of ovarian cancer to Taxanes via IMP-1-mediated stabilization of MDR1. Int J Cancer 2012; 130: 1787-97.

32. Park SM, Shell S, Radjabi AR, et al. Let-7 prevents early cancer progression by supressing expression of embryonic gene HMGA2. Cell Cycle 2007; 6: 2585-90.

33. Johnson CD, Esquela-Kerscher A, Stefani G, et al. The let-7 microRNA represses cell proliferation pathways in human cells. Cancer Res 2007; 67: 7713-22.

34. Shimizu S, Takehara T, Hikita $\mathrm{H}$, et al. The let-7 family of microRNAs inhibits Bcl-xL expression and potentiates sorafenib-induced apoptosis in human hepatocellular carcinoma. J Hepatol 2010; 52: 698-704

35. Jakymiw A, Patel RS, Deming N, et al. Overexpression of dicer as a result of reduced let-7 MicroRNA levels contributes to increased cell proliferation of oral cancer cells. Genes Chromosomes Cancer 2010; 49: 549-59.

36. Andolfo I, De Falco L, Asci R, Russo R, Colucci S, Gorrese M, Zollo M, Iolascon A. Regulation of divalent metal transporter 1 (DMT1) nonIRE isoform by the microRNA Let-7d in erythroid cells. Haematologica 2010; 95: 1244-52.

37. Nuovo GJ, Garofalo M, Valeri N, et al. Reovirus-associated reduction of microRNA-let-7d is related to the increased apoptotic death of cancer cells in clinical samples. Mod Pathol 2012; 25: 1333-44. 
38. Tsang WP, Kwok TT. Let-7a microRNA suppresses therapeutics-induced cancer cell death by targeting caspase-3. Apoptosis 2008; 13: 1215-22.

39. Barh D. Let-7 replacement therapy: applicability in cancer. Cancer Therapy 2008; 6: 969-84.

40. Neilsen CT, Goodall GJ, Bracken CP. IsomiRs - the overlooked reper toire in the dynamic microRNAome. Trends Genet 2012; 28: 544-9.

41. Place RF, Li LC, Pookot D, Noonan EJ, Dahiya R. MicroRNA-373 induces expression of genes with complementary promoter sequences. Proc Natl Acad Sci U S A 2008; 105: 1608-13.

42. Calin GA, Sevignani C, Dumitru CD, et al. Human microRNA genes are frequently located at fragile sites and genomic regions in volved in cancers. Proc Natl Acad Sci U S A 2004; 101: 2999-3004.

43. Zhang L, Huang J, Yang N, et al. microRNAs exhibit high frequency genomic alterations in human cancer. Proc Natl Acad Sci U S A 2006; 103: 9136-41.

44. Zhang B, Pan X, Cobb GP, Anderson TA. microRNAs as oncogenes and tumor suppressors. Dev Biol 2007; 302: 1-12.

45. Lotterman CD, Kent OA, Mendell JT. Functional integration of mi croRNAs into oncogenic and tumor suppressor pathways. Cell Cycle 2008; 7: 2493-9.

46. Esquela-Kerscher A, Slack FJ. Oncomirs - microRNAs with a role in cancer. Nat Rev Cancer 2006; 6: 259-69.

47. Garzon R, Fabbri M, Cimmino A, Calin GA, Croce CM. MicroRNA expression and function in cancer. Trends Mol Med 2006; 12: 580-7.

48. Deng S, Calin GA, Croce CM, Coukos G, Zhang L. Mechanisms of microRNA deregulation in human cancer. Cell Cycle 2008; 7: 2643-6.

49. Lu J, Getz G, Miska EA, et al. MicroRNA expression profiles classify human cancers. Nature 2005; 435: 834-8.

50. Wang Y, Hu X, Greshock J, et al. Genomic DNA copy-number alterations of the let-7 family in human cancers. PLoS One 2012; 7 : e44399.

51. Brueckner B, Stresemann C, Kuner R, Mund C, Musch T, Meister M, Sültmann H, Lyko F. The human let-7a-3 locus contains an epigenetically regulated microRNA gene with oncogenic function. Cancer Res 2007; 67: 1419-23.

52. Ali S, Saleh H, Sethi S, Sarkar FH, Philip PA. MicroRNA profiling of diagnostic needle aspirates from patients with pancreatic cancer. Br J Cancer 2012; 107: 1354-60

53. Nagadia R, Pandit P, Coman WB, Cooper-White J, Punyadeera C. miRNAs in head and neck cancer revisited. Cell Oncol (Dordr) 2013; 36: $1-7$.

54. Liu X, Chen Z, Yu J, Xia J, Zhou X. MicroRNA profiling and head and neck cancer. Comp Funct Genomics 2009; 837514.

55. Chang CJ, Hsu CC, Chang CH, et al. Let-7d functions as novel regulator of epithelial-mesenchymal transition and chemoresistant property in oral cancer. Oncol Rep 2011; 26: 1003-10.

56. Peter ME. Let-7 and miR-200 microRNAs: guardians against pluripotency and cancer progression. Cell Cycle 2009; 8: 843-52.

57. Zhou CH, Yang SF, Li PQ. Human lung cancer cellline SPC-Alcontains cells with characteristics of cancer stem cells. Neoplasma 2012; 59: 685-92

58. Zhao C, Sun G, Ye P, Li S, Shi Y. MicroRNA let-7d regulates the TLX/ microRNA-9 cascade to control neural cell fate and neurogenesis. Sci Rep 2013; 3: 1329

59. Huleihel L, Ben-Yehudah A, Milosevic J, et al. Let-7d microRNA af fects mesenchymalphenotypic properties of lung fibroblasts. Am J Physiol Lung Cell Mol Physiol 2014; 306: L534-42.

60. Pandit KV, Corcoran D, Yousef H, et al. Inhibition and role of let-7d in idiopathic pulmonary fibrosis. Am J Respir Crit Care Med 2010; 182: 220-9.

61. Pandit K, Corcoran D, Yousef $\mathrm{H}$, et al. Let-7d: a regulator of epithelial-mesenchymal transition (EMT) and idiopathic pulmonary fibrosis (IPF). http://www.ashg.org/2008meeting/abstracts/ fulltext/f20337.htm.

62. Chiu SC, Chung HY, Cho DY, et al. Therapeutic potential of micro RNA let-7: tumor suppression or impeding normal stemness. Cell Transplant 2014; 23: 459-69.

63. Sun X, Fan C, Du N, Ren H. Possible carcinogenesis of tumor suppressor let-7. Med Hypotheses 2013; 81: 410-3.

64. Zhang R, He Y, Zhang X, Xing B, Sheng Y, Lu H, Wei Z. Estrogen receptor-regulated microRNAs contribute to the $B C L 2 / B A X$ imbal- ance in endometrial adenocarcinoma and precancerous lesions. Cancer Lett 2012; 314: 155-65.

65. Metheetrairut C, Slack FJ. MicroRNAs in the ionizing radiation response and in radiotherapy. Curr Opin Genet Dev 2013; 23: 12-9.

66. Weidhaas JB, Babar I, Nallur SM, Trang P, Roush S, Boehm M, Gillespie E, Slack FJ. MicroRNAs as potential agents alter resistance to cytotoxic anticancer therapy. Cancer Res 2007; 67: 11111-6.

67. Chaudhry MA, Sachdeva H, Omaruddin RA. Radiation-induced microRNA modulation in glioblastoma cells differing in DNA-repair pathways. DNA Cell Biol 2010; 29: 553-61.

68. Nikiforova MN, Gandhi M, Kelly L, Nikiforov YE. MicroRNA dysregulation in human thyroid cells following exposure to ionizing radiation. Thyroid 2011; 21: 261-6.

69. Simone NL, Soule BP, Ly D, et al. Ionizing radiation-induced oxidative stress alters miRNA expression. PLoS One 2009; 4: e6377.

70. PompJ, Ouwerkerk IJ, HermansJ,WondergemJ, Cornelisse CJ,LeerJW, Schrier PI. The influence of the oncogenes NRAS and MYC on the radiation sensitivity of cells of a human melanoma cell line. Radiat Res 1996; 146: 374-81.

71. Oh JS, Kim JJ, Byun JY, Kim IA. Lin28-let7 modulates radiosensitivity of human cancer cells with activation of K-Ras. Int J Radiat Oncol Biol Phys 2010; 76: 5-8

72. Hummel R, Hussey DJ, Haier J. MicroRNAs: Predictors and mod ifiers of chemo- and radiotherapy in different tumor types. Eur J Cancer 2010; 46: 298-311.

73. Chaudhry MA, Omaruddin RA. Differential regulation of microRNA expression in irradiated and bystander cells. Mol Biol (Mosk) 2012; 46: 634-43.

74. Chaudhry MA. Real-time PCR analysis of micro-RNA expression in ionizing radiation-treated cells. Cancer Biother Radiopharm 2009; 24: 49-56.

75. Lu L, Schwartz P, Scarampi L, Rutherford T, Canuto EM, Yu H, Katsaros D. MicroRNA let-7a: a potential marker for selection of paclitaxel in ovarian cancer management. Gynecol Oncol 2011; 122: 366-71.

76. Boyerinas B, Park SM, Murmann AE, et al. Let-7 modulates acquired resistance of ovarian cancer to Taxanes via IMP-1-mediated stabilization of multidrug resistance 1. Int J Cancer 2012; 130 : 1787-97.

77. Lv K, Liu L, Wang L, et al. Lin28 mediates paclitaxel resistance by modulating $\mathrm{p} 21, \mathrm{Rb}$ and Let-7a miRNA in breast cancer cells. PLoS One 2012; 7: e40008.

78. Yu CC, Chen YW, Chiou GY, et al. MicroRNA let-7a represses chemoresistance and tumourigenicity in head and neck cancer via stem-like properties ablation. Oral Oncol 2011; 47: 202-10.

79. Shell S, Park SM, Radjabi AR, et al. Let-7 expression defines two differentiation stages of cancer. Proc Natl Acad Sci U S A 2007; 104: 11400-5.

80. Volinia S, Galasso M, Sana ME, Wise TF, Palatini J, Huebner K, Croce CM. Breast cancer signatures for invasiveness and prognosis defined by deep sequencing of microRNA. Proc Natl Acad Sci U S A 2012; 109: 3024-9.

81. Jiao LR, Frampton AE, Jacob J, et al. MicroRNAs targeting oncogenes are down-regulated in pancreatic malignant transformation from benign tumors. PLoS One 2012; 7: e32068.

82. Kowalewska M, Bakula-Zalewska E, Chechlinska M, Goryca K, Nasierowska-Guttmejer A, Danska-Bidzinska A, Bidzinski M. microRNAs in uterin sarcomas and mixedepithelial-mesenchyma uterine tummors: a preliminary report. Tumour Biol 2013; 34 2153-60.

83. Childs G, Fazzari M, Kung G, et al. Low-level expression of microRNA let-7d and miR-205 are prognostic marker of head and neck squamous cell carcinoma. Am J Pathol 2009; 174: 736-45.

84. Utsunomiya T, Ishikawa D, Asanoma M, et al. Specific miRNA expression profiles of non-tumor liver tissue predict a risk for reccurence of hepatocellular carcinoma. Hepatol Res 2014; 44: 631-8.

85. Ali S, Almhanna K, Chen W, Philip PA, Sarkar FH. Differentially expressed miRNAs in the plasma may provide a molecular signature for aggressive pancreatic cancer. Am J Transl Res 2010; 3: 28-47.

86. Shiotani A, Murao T, Kimura Y, et al. Identification of serum miRNAs as novel non-invasive biomarkers for detection of high risk for early gastric cancer. Br J Cancer 2013; 109: 2323-30. 
87. Kubiczkova L, Kryukov F, Slaby O, et al. Circulating serum microRNAs as novel diagnostic and prognostic biomarkers for multiple myeloma and monoclonal gammopathy of undetermined significance. Haematologica 2014; 99: 511-8.

88. Chen X, Liang H, Guan D, et al. A combination of let-7d, let-7g and let-7i serves as a stable reference for normalization of serum $\mathrm{mi}$ croRNAs. PLoS One 2013; 8: e79652.

89. Barh D, Malhotra R, Ravi B, Sindhurani P. MicroRNA let-7: an emerging next-generation cancer therapeutic. Curr Oncol 2010; 17: 70-80.

90. Akao Y, Nakagawa Y, Naoe T. Let-7 microRNA functions as a potential growth suppressor in human colon cancer cells. Biol Pharm Bull 2006; 29: 903-6.

91. Kota J, Chivukula RR, O’Donnell KA, et al. Therapeutic microRNA delivery suppresses tumorigenesis in a murine liver cancer model. Cell 2009; 137: 1005-17.

92. Kumar MS, Erkeland SJ, Pester RE, Chen CY, Ebert MS, Sharp PA Jacks T. Suppression of non-small cell lung tumor development by the let-7 microRNA family. Proc Natl Acad Sci U S A 2008; 105: 3903-8.

93. Trang P, Wiggins JF, Daige CL, et al. Systemic delivery of tumor suppressor microRNA mimics using a neutral lipid emulsion inhibits lung tumors in mice. Mol Ther 2011; 19: 1116-22.

94. Pereira DM, Rodrigues PM, Borralho PM, Rodrigues CM. Delivering the promise of miRNA cancer therapeutics. Drug Discov Today 2013; 18: 282-9.

95. Soriano A, Jubierre L, Almazán-Moga A, Molist C, Roma J, de Toledo JS, Gallego S, Segura MF. MicroRNAs as pharmacological targets in cancer. Pharmacol Res 2013; 75: 3-14.

96. Ling H, Fabbri M, Calin GA. MicroRNAs and other non-coding RNAs as targets for anticancer drug development. Nat Rev Drug Discov 2013; 12: 847-65.

97. Jackson AL, Burchard J, Schelter J, Chau BN, Cleary M, Lim L, Linsley PS. Widespread siRNA "off-target" transcript silencing mediated by seed region sequence complementary. RNA 2006; 12: 1179-87.

98. Lebedev TD, Spirin PV, Prassolov VS. Transfer and expression of small interfering RNAs in Mammalian Cells Using Lentiviral Vectors. Acta Naturae 2013; 5: 7-18.

99. Pan Q, de Ruiter PE, von Eije KJ, et al. Disturbance of the microRNA pathway by commonly used lentiviral shRNA libraries limits the application for screening host factors involved in hepatitis C virus infection. FEBS Lett 2011; 585: 1025-30.

\section{Address for correspondence}

\section{mgr inż. Tomasz Kolenda}

Laboratory of Cancer Genetics

Greater Poland Cancer Centre,

Garbary 15, 61-866 Poznan, Poland

e-mail: kolenda.tomek@gmail.com

Submitted: 4.04.2014

Accepted: 18.06.2014 